\title{
Imagens urbanas assombrosas: controle social nas \\ cidades brasileiras da Belle Epoque
}

\author{
Carlos Martins Junior*
}

Frente às transformações estruturais ocorridas na virada do século XIX para o XX, as elites dirigentes brasileiras delinearam um abrangente projeto visando à submissão das camadas populares, fundamentado em dois movimentos simultâneos: promoveu-se uma ideologia valorizadora do trabalho e, sob a justificativa de ordenar o "caos urbano, impunha-se um contínuo esquema de vigilância e repressão do cotidiano da população urbana, processo definido, no plano semântico, como "civilizatório". Propõese refletir sobre os aspectos que ensejaram esse projeto, suas características e os impactos sobre o cotidiano dos populares.

Palavras-chave: Cordenamento urbano. Cotidiano. Camadas populares.

Front on structural transformations that have occurred at the turn of the 19th century to the 20TH Brazilian leadership elites have developed a comprehensive project aiming to grass-roots submission, supported by two simultaneous movements: promoted a fulfilling work and ideology in the justification to order the "urban chaos", it was one continuous surveillance scheme and suppression
V o terço final do século passado, 1 profundas transformações sacudiram a Europa, motivadas pelas formações das grandes propriedades industriais, contrabalançadas pela organização do movimento operário, dos sindicatos e dos partidos trabalhistas e socialistas. Além disso, o ineditismo do crescimento urbano, em ritmo acelerado e desordenado, conferiu às grandes cidades de praticamente todo o mundo o caráter de experiência social mais insólita e crítica do século XIX. ${ }^{1}$

Movidos pela perplexidade e pelo tormento diante da experiência da urbanização, os ingleses, por exemplo, perguntavam-se insistentemente: "o que faremos com as nossas grandes cidades? O que nossas grandes cida-

\footnotetext{
* Professor titular do Curso de História do Campus de Aquidauana da UFMS, membro dos Programas de Mestrado em Estudos Fronteiriços, da UFMS, e em História, da UFGD. E-mail cmartins@dr.com
}

${ }^{1}$ HOBSBAWM, Eric J. A Era do Capital (1848-1875). 2a edição. RJ: Paz e Terra, 1979, p. 42. 
of everyday urban population, the procedure laid down in the semantic plan, such as" civilization ". This article proposes to discuss the aspects that led to that project, its cha- racteristics and the impacts on the daily life of popular.

Key words: Urban planning. Daily life. Popular layers.

des farão de nós?". ${ }^{2}$ Vivenciando o mesmo tormento, intelectuais americanos apelavam para juízos moralizantes, como o de J. N. Ingrahan ao afirmar que "Adão e Eva foram criados e colocados num jardim; as cidades são o resultado da queda". ${ }^{3}$ Do mesmo modo, na França, desde 1833, o doutor Parent - Duchatelet, alarmado com o problema da pressão demográfica em Paris, configurava uma situação de emergência, chegando mesmo a sugerir que os habitantes mais antigos e privilegiados se retirassem da cidade, pois:

[...] desse aumento da população nasceram duas causas que, agindo juntas sem cessar, fizeram desaparecer vantagens que nossos pais vieram procurar na cidade e produziram aqui um estado de coisas que, atualmente, se aproxima da barbárie e que, seja na cidade, seja nas povoações que a cercam, tornou-se intolerável para mais de 100 mil indivíduos. As duas causas concernem, de uma parte, para o agigantamento de Paris e, de outra, ao aumento da massa de matérias suscetíveis de produzir emanações infectas. ${ }^{4}$

Junto ao processo de industrialização e de crescimento urbano, a expansão imperialista, principalmente na África, gerava receios de levantes dos povos conquistados, colocando a questão das fronteiras classistas e raciais entre as mais importantes linhas delimitadoras para a sociedade de diversos países europeus. Analisando as condições específicas da Inglaterra entre as décadas de 1880 e 1890, momento em que a expansão imperial desse país atingia o apogeu, fazendo crescer o receio de degeneração e da queda e levando muitos observadores a comparar o Império Inglês aos Impérios Grego e Romano no período da decadência dos mesmos, afirmou Elaine Showalter, que "enquanto outras raças pareciam distantes e exóticas, a classe operária estava bem à mão". 5

${ }^{2}$ Idem, p. 45.

${ }^{3}$ Apud HOBSBAWM, Eric J. Op. cit., p. 47.

${ }^{4}$ Apud SEVCENCKO, Nicolau. "Perfis urbanos terríveis em Edgar Alan Poe". Cultura e Cidades. São Paulo: ANPUH/ Marco Zero, vol. 5, nº 8/ 9, 1985, pp. 71-72.

${ }^{5}$ SHOWALTER, Elaine. Anarquia Sexual (Sexo e Cultura no Fin de Siècle). Rio de Janeiro: Rocco, 1993, p. 36. 
Devido à forte depressão econômica que atingiu a Europa Ocidental no final da década de 1870, a década seguinte viu nascer o termo "desemprego" e, com ele, uma grave crise na relação entre as classes sociais. O centro das grandes cidades passou a ser percebido como o lugar de concentração do "resíduo", formado por miseráveis crônicos e desempregados "contumazes". Considerando que esse submundo vivia em cortiços, gerando a doença, a ignorância, a loucura e o crime, problemas tidos por muitos analistas como incontornáveis, alguns eugenistas sustentavam, apoiados na tese da degenerescência urbana como fator da deterioração geral da raça, a idéia de que aos pobres não deveria ser permitido o direito de reprodução.

No tocante à questão racial, o temor das rebeliões coloniais, da mestiçagem e dos casamentos inter-raciais despertou o interesse da ciência e da política para com a fixação de linhas demarcatórias bastante nítidas entre brancos e não-bran$\cos$, entre ocidentais e orientais. Assim é que a ciência do período, em especial a antropologia física, devotou-se a estabelecer a legitimidade da hierarquia e da diferenciação sobre as raças e as classes, bem como em demonstrar o perigo da degenerescência física e moral representado pelo desrespeito a esses limites.

Aliás, não faltaram, à época, metáforas raciais para descrever as relações entre as classes. Em Darkest England (1890) e em Darkest London (1891), Willian Booth e Margaret Harkness, respectivamente, traçaram paralelos entre os problemas da selva africana e da selva urbana, onde os desabrigados, a pobreza, a fome, o alcoolismo e a violência sexual podiam ser vistos todos os dias: "Como na África são só arvores, arvores e mais arvores, sem qualquer outra paisagem concebível", escreveu Willian Booth, "da mesma forma ocorre aqui - é só o vício, a pobreza e o crime". ${ }^{6}$ Explicitamente, tudo o que era escuro ou labiríntico podia estar localizado na África, no Oriente ou mesmo nos bairros operários de Londres ou de qualquer outra grande cidade do Ocidente. Fosse por medo ou compaixão, o confinamento da pobreza nos bairros operários, a carência de habitações urbanas e o desemprego geral eram estados de coisas que despertavam as atenções dos homens de saber e do cidadão comum, cuja imaginação era mais estimulada quanto maior o número de publicações sobre esses assuntos nos jornais.

${ }^{6}$ Apud SHOWALTER, Elaine. Op. cit., p. 19 
Durante a segunda metade do século XIX, também o Brasil passou por mudanças estruturais que se refletiam na paisagem urbana. A progressiva substituição da mão-de-obra escravista pelo trabalho livre assalariado, o surgimento das fábricas, o desenvolvimento dos sistemas de circulação de mercadorias, além do crescimento demográfico, acentuado pela chegada de crescentes levas de imigrantes europeus e pela incorporação à população urbana de elementos étnicos nacionais (negros e mestiços) provenientes das áreas rurais, fizeram com que o Rio de Janeiro perdesse por completo, no decorrer das três últimas décadas do século XIX, o caráter provinciano e colonial que até então conservara.

Quanto ao problema da pressão demográfica, dados do censo de 1890 informam que o Distrito Federal possuía 521.651 habitantes, 81\% deles vivendo na área urbana propriamente dita. Os números revelam, ainda, que entre $1872 \mathrm{e}$ 1890 a população da capital do país havia praticamente duplicado em termos absolutos. Paralelamente à expansão demográfica e física da cidade, acentuavamse as atividades econômicas, trazendo como conseqüência maior complicação do perfil social urbano, que passou a ser caracterizado pelo descompasso entre a (abundante) oferta e a (escassa) procura por mão-de-obra, fato que promovia a maximização da exploração do trabalho e a conseqüente redução salarial.

Algumas estatísticas destacando o nível de emprego na Capital Federal mostram que a quantidade de desocupados ou pessoas tidas como sem profissão declarada atingia, na última década do século XIX, 48.110 indivíduos, representando cerca de 9,20\% da população total da cidade. ${ }^{7}$ Para esses elementos, que ficavam à margem do mercado regular de trabalho (a maioria negros e mulatos), viver do pequeno comércio e de expedientes era uma estratégia de sobrevivência.

Em A Alma Encantadora das ruas, João do Rio cita alguns exemplos daquelas atividades que denominou de "profissões da miséria", relacionando entre elas as de trapeiro, cavoqueiro, caçadores de ratos, coletores de botas, tatuadores, vendedores ambulantes de orações e literatura de cordel, compositores de modinhas, etc. A essas podem ser acrescentadas as atividades femininas ligadas aos serviços domésticos, ao pequeno comércio (quitandeiras e quituteiras), ao arte-

${ }^{7}$ LOBO, Eulália M. L. História do Rio de Janeiro (Do Capital Comercial ao Capital Industrial). Rio de Janeiro: IBMEC, 1978. 
sanato (em especial o serviço de costureira), além das cartomantes, curandeiras, amamentadoras (amamentação mercenária assalariada), coristas, dançarinas, cantoras, atrizes e vendedoras de charutos, entre outras. ${ }^{8}$ Todas elas atividades bastante depreciadas à época, a ponto de incluir as mulheres que as exerciam na categoria dos "sem profissão declarada" e, não raro, associá-las à prostituição. ${ }^{9}$

Claro está que não só desses expedientes vivia o "povo das ruas". Gerado, sustentado e reproduzido pela modernização, um mundo marginal constitui-se, fazendo emergir novos personagens urbanos como ladrões, punguistas, vigaristas, jogadores, bêbados, traficantes de mulheres e de drogas, gigolôs, prostitutas e mendigos, entre outros.

Da mesma forma que o Distrito Federal, entre 1870 e 1900 São Paulo foi palco de intenso crescimento, tornando-se, segundo Richard Morse, "uma cidade completa e economicamente ativa", passando do décimo para o segundo lugar em tamanho no país, superada apenas pelo Rio de Janeiro. ${ }^{10}$ Conseqüentemente, também ali o avanço do capitalismo resultou em elementos complicadores do social, na dificuldade de adequação da relação entre demanda e oferta de empregos, de habitações e na necessidade de adaptar a melhoria dos serviços públicos ao crescimento populacional e físico da cidade.

Ao que tudo indica, portanto, as três últimas décadas do século XIX representaram, para os habitantes das grandes metrópoles brasileiras, um período de alteração da qualidade de vida, cristalizado no sentimento de perda definitiva de um mundo idílico, anteriormente caracterizado pela ordenação quase doméstica da vida social. Toda a dramaticidade dessa mudança de sensibilidades refletia-se na imprensa e na literatura. Descrevendo a situação do Rio de Janeiro na virada do século, Luiz Edmundo definia a cidade como:

[...] um monstro onde as epidemias se albergam dançando sabats magníficos, aldeia melancólica de prédios velhos e acaçapados a descascar pelos rebocos, vielas sórdidas cheirando mal, exceção feita da que se chama Rua do Ouvidor, onde [...] o homem do "burro-sem-rabo" cruza com o elegante da região tropi-

\footnotetext{
${ }^{8}$ RIO, João do. A Alma Encantadora das Ruas. Rio de Janeiro: Simões, 1951.

${ }^{9}$ MACEDO, Francisco Ferraz de. Da Prostituição em Geral. Rio de Janeiro: Typographia Acadêmica, 1873.
}

${ }^{10}$ MORSE, Richard. Formação Histórica de São Paulo. São Paulo: DIFEL, 1970, p. 216. 
cal, que traz no mês de fevereiro sobrecasaca preta de lã inglesa, e [...] dilui-se em cachoeiras de suor. ${ }^{11}$

Em São Paulo era através da imagem da desfiguração dos valores morais, sociais e culturais que a imprensa, por exemplo, referia-se às mudanças pelas quais a cidade passava, como mostra o trecho do artigo extraído do jornal Diário Popular, de 27 de outubro de 1893, onde se lê:

São Paulo caminha para a perdição moral. Para qualquer parte que se vire, o visitante encontra o vicio a desenvolver-se com desbragamento tal, que preciso se faz a intervenção dos poderes públicos para impedi-lo. Outrora, em ruas onde só se encontravam famílias e casas habitadas por quem tem o que fazer se vêm hoje caras impossíveis, mostrando-se embora cobertas de col creme Simon, pulvilhado (sic) pelo pó-de-arroz, os sulcos que não se extinguem, deixados pelos deboches e pelas noites em claro libando, em desenvolta imoralidade, as taças de champanhe falsificado, entre os pechisbeques do falso amor.

Por outro lado, referências à oposição entre o caráter corrompido do homem urbano em relação à pureza e à simplicidade naturais, que o individuo originário do campo ainda conservava, são freqüentemente encontradas na literatura da época. Entre tantos exemplos, Adolfo Caminha, mesmo tendo como cenário uma capital de menor porte, Fortaleza, tratava do tema da seguinte maneira:

Mendonça conhecia Fortaleza superficialmente; suas viagens à capital tinham sido raríssimas; viera vezes contadas a negócios. Sabia os homens propensos ao mal, [...], porém a vida ruidosa e dissoluta das capitais, esse tumultuar cotidiano de virtudes fingidas e vícios inconfessáveis, esse tropel de paixões desencontradas, isso que se constitui, por assim dizer, a maior felicidade do ser humano, esse acervo de mentiras galantes e torpezas dissimuladas, esse cortiço de vespas que se denomina sociedade, desconhecia-o ele e nem sequer imaginava. $^{12}$

O fato é que a diversificação das atividades econômicas, acrescida da maior complexidade da estrutura social, transformava a paisagem urbana em algo cada dia mais desconhecido e assustador aos olhos dos médicos, juristas, políticos e reformadores sociais que pretendiam ordená-la. Concebendo os centros urbanos

${ }^{11}$ EDMUNDO, Luiz. Rio de Janeiro em Prosa e Verso (coletânea). Rio de Janeiro: Livraria José Olympio Editora, 1965, p. 21.

${ }^{12}$ CAMINHA, Adolfo. A Normalista. 4a edição. São Paulo: Ática, 1976, p. 27. 
como verdadeiros laboratórios de observação, esses agentes sociais produziram em relação a eles imagens extremamente contraditórias.

De um lado, as melhorias materiais das cidades - como a construção, ampliação e remodelação de ruas e avenidas, a instalação de novos sistemas de iluminação, saneamento básico e transportes - e a busca de novas formas de lazer e prazer simbolizavam a reprodução, em nível nacional, dos padrões de comportamento europeus, fazendo com que o espaço urbano fosse representado como emblema da modernidade e do progresso, a vitória da "civilização" sobre o passado colonial fortemente marcado pela vida rural. O grande burburinho das ruas, a alegria vivenciada nos cafés, restaurantes, bordéis, teatros e confeitarias, bem como a presença de famílias inteiras nas ruas e nos passeios públicos ali estavam para confirmá-lo. De outro lado, as agitações operárias, a concentração da pobreza e a exposição pública do trabalho sustentaram, no plano das mentalidades, a edificação de imagens das cidades como símbolos do caos, locais de ajuntamento, nas áreas centrais e em cortiços insalubres, de uma multidão miserável e indisciplinada capaz de esconder, em suas entranhas, o vício, a doença e o crime.

Permanentemente associada à visão da pobreza presente nas ruas, a multidão transformou-se em sinônimo de contágio físico, moral e de ameaça política, incutindo nas mentes pensantes a preocupação com a possibilidade da propagação de doenças físicas e o medo do desencadeamento e uma verdadeira onda de crimes contra a pessoa e a propriedade, ocasionada pela degenerescência dos costumes.

Em suma, as sensações de medo, espanto e indignação frente à presença e ao contato com a miséria, associada à correlação que se estabelecia entre crescimento urbano, pobreza e criminalidade, reforçaram, na mente dos intelectuais e do homem das camadas mais bem postas da sociedade, imagens da cidade como lugar privilegiado para o florescimento de tensões e esforços anormais capazes de degradar física e moralmente os indivíduos e as relações sociais, implicando o surgimento do receio de uma crise eminente que viria a afetar, essencialmente, a família, instituição tida como a base de todo o ordenamento social. Esses ingredientes promoveram mudanças radicais nas concepções e práticas da saúde, bem como na noção e abrangência da criminalidade. Foi nesse contexto que ocorreu o processo da naturalização do crime e o conseqüente crescimento do interesse por sua medicalização. 
Contando com a cobertura teórica do darwinismo social e do positivismo, a nova forma de pensar e representar o espaço urbano intensificou o desejo das elites e dos poderes públicos em aprofundar estratégias de controle das camadas populares, vistas como substratos produtores de prostitutas, vadios, bêbados e agitadores operários. A partir daí, os diferentes "desvios" passaram a ser crescentemente separados e classificados, e para cada um deles desenvolveram-se formas especificas de enfrentamento, respaldadas na noção de ciência como fundamento do progresso.

No concernente à ação policial sobre os populares, São Paulo serviu de exemplo para o resto do país. Em 1892 surgiram as primeiras estatísticas sobre a criminalidade na capital, transformando São Paulo no único estado a possuir esse serviço organizado. ${ }^{13}$ Em 1893, organizou-se um dos melhores censos demográficos da capital, sucedido, no ano de 1894, pelas primeiras prisões de lideranças operárias por ocasião das comemorações do Primeiro de Maio. Além disso, em 1897 foi criado, sob inspiração do então delegado Cândido Motta, o Regulamento Provisório da Polícia de Costumes, com a finalidade de regulamentar e disciplinar a prostituição. ${ }^{14}$ Sem contar que, culminando com o acirramento da campanha realizada durante toda a década de 1890 contra a presença nas ruas de menores "arruaceiros" e abandonados, foi fundado, em 1902, o Instituto Disciplinar.

Mas a prova cabal do receio "indefinido do crime" por parte das elites urbanas foi a completa reformulação promovida na estrutura interna e na mentalidade da instituição policial em relação à criminalidade e ao combate da mesma. ${ }^{15} \mathrm{Os}$ relatórios dos chefes de polícia da cidade de São Paulo mostram que, entre 1892

\footnotetext{
${ }^{13}$ CASTRO, Francisco José Viveiros de. Atentados ao Pudor. Sobre as aberrações do instinto sexual. $3^{\text {a }}$ edição. Rio de Janeiro: Freitas Bastos, 1934, p. 58.

${ }^{14}$ Ver a respeito MOTTA, Candido. "Prostituição - Polícia de Costumes - Lenocínio". Relatório Apresentado ao Exmo Sr. Dr. Chefe de Polícia da Capital. São Paulo: Imprensa Oficial, 1897.

${ }^{15}$ A respeito do tema, ver, entre outros, BRUNO, Ernani da Silva. "Três aspectos do policiamento de São Paulo no século XIX”. Revista Investigação, no 2, 1947; FAUSTO, Boris. Crime e cotidiano: a criminalidade em São Paulo (1880-1924). São Paulo: Brasiliense, 1984; NEDER, G. e NARO, N. P. "A instituição policial no Rio de Janeiro e a construção da ordem burguesa no Brasil". Policia na Corte e no Distrito Federal (1831-1930). Rio de Janeiro: PUC/RJ, Série Estudos, no 3, 1981; BRANDÃO, Berenice C. A Policia e a Força Policial no Rio de Janeiro. Rio de Janeiro: PUC/RJ, Série Estudos, nº 4, 1981.
} 
e 1916, houve um aumento paulatino da preocupação das autoridades policiais no tocante à proteção dos "bons costumes".

Em Relatório apresentado à Secretaria de Justiça de São Paulo no ano de 1896, o Chefe de Polícia, doutor Bento Pereira Bueno, queixava-se da insuficiência do efetivo policial, que não acompanhava o ritmo do crescimento da população, afirmando que, em conseqüência disso, "a ação da policia não se tem até aqui verificado com a desejável regularidade", tornando quase impossível "a guarda dos costumes tão necessária nas grandes cidades". ${ }^{16}$ Nesse processo de "guarda dos costumes", estava na mira da polícia a eliminação de contravenções como a vadiagem, que associada à mendicância era vista como o principal receptáculo da delinqüência; a desordem, referida em relação ao comportamento das pessoas em público, podendo incluir também as ações dos grevistas; a embriagues, contravenção próxima da desordem; e a prostituição que, embora não estivesse prevista como crime no Código Penal, colocava a mulher sob a rubrica da vadiagem.

Outro dado revelador de que a atividade policial extrapolava, em muito, o combate à criminalidade real é a defasagem entre o número de detenções para averiguação e o de prisões com processos. Levando-se em consideração que os anos de 1892 a 1905 corresponderam, em São Paulo, ao pico das detenções para averiguação (84\% das detenções efetuadas), e considerando-se, ainda, que esse período coincidiu com o acirramento das transformações ocorridas na cidade e com a recessão ocasionada pela crise cafeeira, iniciada por volta de 1898 , conclui-se que a atividade repressiva da polícia visava, acima de tudo, ao controle social. Percebendo os populares como arruaceiros, trabalhando com a idéia de naturalização do desvio e com pares opostos de conceitos, em que a rua representava o mal, e a casa, o trabalho e a escola o bem, a tarefa da polícia era realizar uma verdadeira intervenção nos espaços públicos, a fim de manter a ordem ameaçada pelos infratores das normas do bom viver. ${ }^{17}$

Ressalte-se que essa preocupação intervencionista de cunho moralizante crescia e refinava-se em proporção direta ao crescimento da organização e das

\footnotetext{
${ }^{16}$ Relatório Apresentado ao Secretário dos Negócios da Justiça de São Paulo pelo Chefe de Policia Bento Pereira Bueno, em 31 de janeiro de 1896. São Paulo: Imprensa Oficial, 1896, p. 173.

${ }^{17}$ FAUSTO, Boris . Op. cit., p. 112.
} 
reivindicações operárias, atingindo, em meados da década de 1910, dimensões nacionais. Um ano depois da greve geral de 1917 realizou-se, no Rio de Janeiro, uma conferência Judiciária-Policial, na qual as autoridades presentes procuravam definir, com a máxima clareza, estratégias conjuntas de atuação dos poderes públicos sobre a delinqüência e a moralidade pública. Significativa nessa Conferência foi a explanação do doutor Celso Vieira de Mello, a respeito do conceito de moralidade pública. Afirmando que, do ponto de vista policial, tal conceito era ainda muito vago, propunha que o mesmo fosse aplicado à vigilância das ruas, compreendendo os crimes de ultraje público ao pudor, as contravenções aos regulamentos de polícia, das leis penais e das posturas municipais, além de “todos os casos que, não previstos nas posturas e regulamentos, ou previstos sob outros aspectos, possam ofender eventualmente [...] o pudor, a dignidade e o recato dos cidadãos em tudo quanto se refere à pública observância dos bons costumes". ${ }^{18}$ Definindo como local público a "qualidade do lugar e não a presença de testemunhas, que em todos os casos de ultraje público ao pudor ou ofensa aos bons costumes requer a intervenção policial", o doutor Celso Vieira de Mello propunha ainda a ampliação do campo de atuação da polícia entendendo que, para além dos caminhos, praças, igrejas, botequins, estalagens, hospedarias, etc., o mesmo deveria ser alargado para todos os lugares expostos ao público, a exemplo de "uma casa que tenha a porta aberta, deixando ser visto, fora, o que se passa no interior". ${ }^{19}$

Paralelamente a isso, iniciou-se uma maior intervenção do Poder Público no processo de reformulação da própria configuração do espaço físico das cidades. Devido ao sem-número de "cantos", à confusão de pessoas anônimas nas ruas e à população pobre que se concentrava em casas de cômodos, becos e vielas, os grandes centros urbanos brasileiros, em especial do Rio de Janeiro, transformavam-se em abrigo de fugitivos e ex-escravos, constituindo o que Sidney Chalhoud definiu como "cidades esconderijos". ${ }^{20}$ Em decorrência, qualquer motim tornava-se, como destacaram Nicolau Sevcencko e José Mu-

${ }^{18}$ PEREIRA, Celso Vieira de Mello. "A rua sob o ponto de vista moral”. Anais da Conferência Judiciária-policial. Rio de Janeiro: Imprensa Nacional, 1918, pp. 478-479.

${ }^{19}$ PEREIRA, Celso Vieira de Mello. Op. cit., p. 480.

${ }^{20}$ CHALLHOUB, Sidney. Visões de Liberdade. São Paulo: Cia das Letras, 1990. 
rilo de Carvalho ${ }^{21}$, praticamente incontrolável, caso exemplar de Revolta da Vacina. Não foi por acaso, portanto, que em São Paulo (mais lentamente) e no Rio de Janeiro as reformas urbanas acompanharam de perto o modelo parisiense do pós-movimento da comuna de $1871 .^{22}$

Informados pelas teorias dos miasmas e dos micróbios, as quais permitiram o surgimento da metáfora do corpo orgânico que percorreu toda a fala médica quando esta se referia à sociedade, os médicos-sanitaristas acabaram se destacando como maestros das reformas urbanas. No intuito de proteger, cuidar e assepsiar o corpo social da insalubridade presente nos fluidos (no ar e na água), a partir dessas duas concepções médicas promoveu-se a instalação de redes de esgotos para distanciar as imundícies dos centros das cidades, a canalização de águas, a criação de serviços de higiene e a introdução de áreas verdes e jardins públicos. Mais que isso, a utilização da metáfora da virtualidade da doença (física, moral e social) contribuiu para promover uma verdadeira reorientação do pensamento e da prática dos poderes públicos em relação à criminalidade, pois, a partir daí, a atuação dos médicos sanitaristas deveria recair sobre todo o espaço social urbano, sobre toda a população e não mais ficar restrita aos chamados "focos infecciosos" como cabarés, botequins, bordéis, fabricas, etc.

Seguindo o modelo higienista, a ação da polícia e da Justiça não deveria incidir exclusivamente sobre os criminosos comprovados. Distante disso, surgindo perante o olhar da polícia médica como portadores de "vícios" e paixões incontroláveis (portanto, corruptíveis a priori), associados a cheiros fortes e à selvageria, foram os membros da população pobre e trabalhadora, através de seus hábitos cotidianos, o alvo da ação intervencionista e disciplinadora encetada pelas autoridades, a fim de recuperar o corpo social segundo as leis da natureza. Assim, paralelamente à higienização dos espaços públicos, os saberes-poderes brasileiros do final do século XIX e início do XX focaram suas atenções sobre a "assepsia" das habitações populares, apontadas como locais de transmissão da

${ }^{21}$ SEVCENCKO, Nicolau. A Revolta da Vacina. São Paulo: Brasiliense, 1984; CARVALHO, José Murilo de. Os Bestializados. São Paulo: Cia das Letras, 1987.

${ }^{22}$ PECHMAN, Sérgio e FRITSCH, Lílian. "A reforma urbana e seu avesso: algumas considerações a respeito da modernização do Distrito federal na virada do século". Cultura e Cidades. São Paulo: Marco Zero/ANPUH, vol. 5, nº 8/ 9, 1985. 
doença. Com isso, preparava-se a intervenção na vida privada dos indivíduos, sob a justificativa da necessidade de higienizar o "meio viciado".

Exemplos disso são os Códigos de Posturas Municipais, que passaram a definir critérios de construção de prédios para conferir-lhes uma padronização mais de acordo com o processo de modernização urbana. Eulália Lobo informa que desde a década de 1880 discutia-se, no legislativo carioca, o problema dos cortiços como fator da baixa produtividade dos operários. ${ }^{23}$ Em São Paulo, o mesmo desejo intervencionista fazia-se sentir no mínimo desde 1886, como se observa no Código de Posturas Municipais desse ano, em especial no capítulo referente aos "Cortiços, Casas Operárias e Cubículos", bem como no Código Sanitário Decretado pelo Estado de São Paulo em 1894, sobretudo o capítulo dedicado às "Habitações Populares e Casas dos Pobres".

Vale destacar, que esse padrão de ordenamento das áreas públicas e de regulamentação de condutas morais e sociais reproduzia-se também em cidades de menor porte do interior do país, a exemplo de Campo Grande, atual capital de Mato Grosso do Sul, cujo primeiro Código de Posturas, aprovado em 1905, previa, no parágrafo $1^{\circ}$, do Artigo $44^{\circ}$ do Capítulo $9^{\circ}$, a proibição de "ajuntamento, nas tabernas ou casas de bebidas, de pessoas que não estejam comprando”, com pena prevista, aos infratores, de seis mil réis ou dois dias de prisão. Além disso, destacava o Capítulo $10^{\circ}$ :

Reunião prohibida e offensas a moral:

Art $45^{\circ}$ É expressamente prohibido;

$\S 1^{\circ}$ Fazer-se bulha ou algazarra e dar gritos a noite.

$\S 2^{\circ}$ Fazer-se sambas, Catiretes (sic), ou quaesquer brinquedos que produzam estrondo ou vozeria dentro da Villa.

$\S 3^{\circ}$ Proferir palavras obscenas ou licenciozas que offendam a moral publica.

$\S 4^{\circ}$ Escrevinhar nas paredes das casas, ou muros ou desenhar figuras indecentes ou garatujas.

Os infratores deste artigo e seus paragraphos ficam sujeitos a multa de $10 \$ 000$ ou cinco dias de prisão. ${ }^{24}$

${ }^{23}$ LOBO, Eulália M. L. "Condições de vida de artesãos e do operariado no Rio de Janeiro nas décadas de 1880 a 1920”. Nova Americana. Turim: Julio Einaudi, № 4, 1981.

${ }^{24}$ ARCA. Revista de Divulgação do Arquivo Histórico de Campo Grande-MS. Campo Grande: $\mathrm{n}^{\circ}$ 5, outubro de 1995 ("1 Código de Posturas Municipais da Villa de Campo Grande”, separata). 
Conforme Jacques Donzelot, as imagens elaboradas no Brasil sobre as casas populares eram muito semelhantes àquelas produzidas pelos médicos sanitaristas europeus, para quem "o hábito de viver em casas e cômodos, de fazer refeições em tabernas, de preferir, em suma, viver-se na rua, viver em cabarés", era entendido como razão da "decadência física e independência moral da classe operária". Percebidas como imorais e insalubres, combater as moradias populares transformavase, então, numa luta contra um habitat visto como "abrigo, lugar de defesa da autonomia". Assim, o principal objetivo de médicos e reformadores urbanos era fazer com que os operários, conservando "bem" sua moradia, criassem apego à ordem pública, reduzindo a parte social da casa em favor de espaços reservados à família (pais e filhos), como forma de facilitar o exercício da vigilância. Procedendo dessa maneira, ficariam mais próximos da intimidade do lar e, conseqüentemente, distantes dos cabarés. ${ }^{25}$ Noutros termos, se o lar era o local da formação de indivíduos privativos e felizes no interior da família, seu antípoda, o cortiço (a não-casa) era concebido como espaço onde teriam origem os mais abjetos males físicos e morais, capazes de infectar o "corpo social". Assim, ao privilegiar a necessidade de penetrar nas casas populares como forma de "corrigir o meio", a medicina refletia não só a intenção de examinar e classificar os "desvios", mas também o desejo burguês de levar o ideal da família higiênica aos pobres e trabalhadores, no intuito de corrigir os males detectados na sociedade.

Talvez nenhum outro aspecto da vida cotidiana tenha despertado mais interesse de intelectuais, políticos, reformadores sociais e dos órgãos públicos brasileiros do final do século XIX, do que as práticas afetivo-sexuais elaborados pelos indivíduos dos chamados "grupos sociais subalternos". Segundo Michel Foucault, tal interesse se explica por que "nas relações de poder, a sexualidade não é o elemento mais rígido, mas um dos elementos de maior instrumentalidade: utilizável no maior número de manobras e podendo servir de ponto de apoio, de articulação das mais variadas estratégias". ${ }^{26}$

Com efeito, no processo de construção de um saber voltado para a normatização e a administração política dos mais abrangentes aspectos da vida coti-

\footnotetext{
${ }^{25}$ DONZELOT, Jacques. A Policia das Famílias. Rio de Janeiro: Graal, 1980, pp. 38-43.

${ }^{26}$ FOUCAULT, Michel. História da Sexualidade I: A Vontade de Saber. $3^{\text {a }}$ edição. Rio de Janeiro: Graal, 1980, p. 31.
} 
diana dos habitantes das grandes cidades, e palmilhando os mesmos caminhos percorridos pela ciência européia em direção à edificação de um discurso sobre o sexo, também os saberes-poderes brasileiros do século XIX demonstravam uma preocupação cada vez maior com a sexualidade, expressa, por exemplo, na crescente abordagem de temas como a homossexualidade, a prostituição, o onanismo, o amor, o casamento, etc. Portanto, no Brasil, como em tantas outras partes do mundo ocidental, intensificava-se um esquema no qual "a vontade de saber do cientista" transformava o corpo e o prazer em objetos de conhecimento, formulando discursos sobre o sexo que não constituíam unicamente discursos morais, mas da própria racionalidade.

Repetindo o esquema de produção da sexualidade inaugurado na Europa em fins do século XVIII, também aqui se esboçara, desde meados do século XIX, uma "ciência sexual" que se apresentava como instrumento capaz de reconhecer o certo e o errado, o verdadeiro e o falso, em matéria de sexo. Em linhas gerais, as tecnologias de higienização e normatização dos prazeres sexuais trazidos pela "nova ciência" objetivavam a maximização da vida, a proibição do incesto, o crescimento demográfico e urbano ordenado, bem como controle familiar da população.

Nesse sentido, escamoteadas pelo discurso da modernidade, as reformas urbanas no Brasil da virada do século XIX para o XX revelam o projeto das elites locais de separar, de forma mais rígida, os espaços público e privado, ou seja, sua política de separação de corpos, fato que se torna notório quanto mais se sabe que a população pobre pouco ou nada desfrutou da maior parte das melhorias trazidas com o processo de "remodelação" e "embelezamento" das cidades brasileiras. Na realidade, as casas de cômodos existentes nos centros das cidades foram demolidas ou remodeladas, logradouros públicos como chafarizes e quiosques, espaços de sociabilidade privilegiados dos populares, começaram a desaparecer, num movimento crescente que visava à normalização do que era percebido como comportamento desordenado da população. ${ }^{27}$

Definido como espaço burguês por excelência, lugar dos negócios, do luxo e das mercadorias, o centro da cidade foi praticamente vetado às camadas populares, que nesse processo de exclusão foram cada vez mais empurradas para as periferias e subúrbios, onde surgiram novas casas "doentes" como os cortiços

${ }^{27}$ PECHMAN, Sérgio e FRITSCH, Lílian. Op. cit. 
dos bairros operários de São Paulo, ou a "nova África" e as favelas dos morros cariocas. A rigor, na cidade do capital o espetáculo da pobreza e do trabalho não deveria ocupar lugar algum, mas sim ser isolado, disciplinado e marginalizado. Exemplo significativo desse esquema de exclusão aparece no depoimento dado por dona Alice a Ecléia Bosi:

Quando eu trabalhava, nem para o centro da cidade eu ia. Minha vida era da Marques de Itu para o Bom Retiro, para mim não tinha cidade. Mais tarde quando conheci a cidade, ela era uma maravilha [...]. O centro da cidade era bonito, era bonito sim! As mulheres andando de luvas e chapéu na cidade, como num passeio. ${ }^{28}$

Paralelamente, como bem observou Robert D. Storch para as condições específicas da Inglaterra na primeira metade do século XIX ${ }^{29}$, no Brasil do final do século XIX e início do XX as reformas da polícia e da justiça penal refletiram, acima de tudo, o advento de noções redefinidoras dos elementos constituintes da ordem e da disciplina social. Daí em diante, o policiamento urbano desempenharia importante papel na tentativa de estabelecer novos, e mais estreitos, limites de comportamentos toleráveis, em que o permitido e o tolerado em público deveriam ser enormemente reduzidos.

Por outro lado, influenciados pela cadeia perversão - degenerescência - hereditariedade, criada pela medicina, e pela noção de que a desordem social corrente no país tinha origem na constituição anômala do homem, a qual precisava ser corrigida, também os agentes responsáveis pela aplicação da lei estiveram envolvidos no esquema de normatização e moralização das condutas cotidianas das camadas populares, que, em ultima análise, visava à formação do cidadão morigerado e trabalhador. Os artigos que compunham o Título $8^{\circ}$ do Código Penal de 1890, o qual tratava "Da Segurança da Honra e da Honestidade das Famílias e do Ultraje Público ao Pudor"30, atestam não só a mudança de um

\footnotetext{
${ }^{28}$ BOSI, Ecléia - Memória e Sociedade. Lembrança de Velhos. $2^{\mathrm{a}}$ edição. São Paulo: Cia das Letras, 1987 , p. 60.

${ }^{29}$ STORCH, Robert D. “O policiamento do cotidiano na cidade vitoriana”. Cultura e Cidades. São Paulo: ANPUH/ Marco Zero, vol. 5, nº 8/ 9, 1985

${ }^{30}$ No Código Penal de 1890, o Titulo $8^{\circ}$ inseria-se no capítulo referente à Violência Carnal, dando tratamento individualizado aos delitos de atentados ao pudor (art. 266), defloramento (art. 267), estupro (art. 268 e 269), rapto (art. 270 e 271), adultério (art. 277 e 278) e ultrajes públicos ao pudor (art. 282). In: CAMARGO, Hypólito de. O Código de 1890. São Paulo: Teixeira e Irmão Editores, 1890.
} 
sistema de detecção e de punição de alguns poucos para outro de vigilância de muitos, como o fato de que, quaisquer que tenham sido as realizações do Direito Penal do período em matéria de combate aos crimes de maior gravidade (e essas não foram poucas), a vigilância, a autorização oficial e a regulamentação do cotidiano, o combate aos pequenos crimes e à grande quantidade de transgressões tecnicamente não criminosas estiveram no centro do projeto de ordem pública desenvolvido pelas classes dominantes brasileiras da virada do século XIX para o XX. 